\title{
Expressive writing changes grief into meaning - a sequential explanatory design approach
}

\author{
Setiawati Intan Savitri ${ }^{*}$, Bagus Takwin ${ }^{2}$,Amarina Ashar Ariyanto ${ }^{3}$, Rachel T.A \\ Aribowo $^{4}$ \\ ${ }^{1}$ Universitas Mercubuana, Indonesia \\ ${ }^{234}$ Universitas Indonesia, Indonesia, \\ ${ }^{*}$ Corresponding author, ఏ"
}

\begin{abstract}
The purpose of the present study was to describe the effect of expressive writing on the level of one's grief through a sequential design (expressive writing experiments for 3 consecutive days for 15 minutes each days then an analysis of the participant's writing contents was conducted). This study used a pre-post test matching technique experimental design follow up by content analysis. The total number of participants (both in the experimental and control groups) was $30(\mathrm{M}$-age $=21.2$; $\mathrm{SD}=1.2)$, lost their parents more than six month. Randomized matching technique was use to divide participant into experimental (expressive writing) and control (non-expressive writing). The baseline score measured by the complicated grieving inventory of $>25$ (Prigereson, 1995). Results showed that the experimental group had a decreased level of grief relative to the control group, the texts showed an interested result to be further discussed.
\end{abstract}

Keywords: Complicated-grief, ICG, expressive writing, sequential explanatory

How to Cite: Savitri, S., Takwin, B., Ariyanto, A., \& Aribowo, R. (2019). Expressive writing changes grief into meaning - a sequential explanatory design approach. COUNS-EDU: The International Journal of Counseling and Education, 4(3), 102-113. DOI: https://doi.org/10.23916/0020190423740

\section{Introduction}

Grieving is a normal symptom of an individual who loses someone or something he or she loves ((Stroebe, 2010). However, some expert divided grieving into two different classifications: typical grief and atypical grief. A typical grief is characterized by protest and despair, including the emergence of the symptoms of physical disorders, such as lethargy and feelings of being unable to escape from the past but, over time, it can eventually subside and is accepted (Bonanno et al., 2002). An atypical grief is one not subsided for more than a year, referred to as a prolonged grief disorder or complicated grief, or persistent complex bereavement disorder (Lundorff, Holmgren, Zachariae, Farver-vestergaard, \& Connor, 2018; Prigerson et al., 2009). The signs of this last symptom include a sense of prolonged loss not subsided by time, always feeling the deceased near and nearby, performing mummification or organizing items or property of the deceased, which are not allowed to be changed, as if the latter is still alive, as well as numbness not disappearing after one week of events (Bowlby, n.d 2008.)

Handling of negative emotions due to the loss of either someone or something by means of expressive writing has been researched by (Chung \& Pennebaker, 2007). Expressive writing, that asks participants to express their deepest thoughts and feelings during four days in a consecutive days for 30 minutes per day proved to effectively cope with negative feelings. It produces adaptive effects in various 
contexts of loss, such as in breast cancer patients (Lu, Gallagher, Loh, \& Young, 2018) in those who lost their jobs (Chung \& Pennebaker, 2007), those who lost a partner in a romantic relationship or had a broken heart (Lepore \& Greenberg, 2002). However, studies linking the effects of expressive writing to the loss of parents or one of the parents are scant (Frattaroli, 2006). In the context of Indonesia, studies aimed at determining the effects of expressive writing on the negative emotions were only conducted in the context of depression in general (Fitria Ida et al., 2016; Qonitatin, Widyawati, \& Asih, 2001), but none specifically linked it to the context of prolonged grief due to the loss of parents or one of parents, or complicated grieving. Furthermore, in addition to their scarcity, studies of the effects of expressive writing on prolonged-grieving individual had varied results. A study by (Rubin et al., 2019) showed that expressive writing on the topic of positive memory for the deceased did not have a significant effect on mood changes; however, (Boals, 2012) and (Bonanno, 1997) studies showed the opposite, in which expressing a negative feeling through writing could reduce the symptoms of grieving, changing the mood to be more adaptive, and also meaning making. With regard to emotional disclosure by means of expressive writing (both positive and negative) the study of (Stroebe,M., Schut., 2005) showed no significant effect on adaptation.

Thus, the purpose of the present study was to explain and confirm the effects of expressive writing on the levels of prolonged grieving caused by the loss of parents. It is thought that when someone discloses (not keeping, suppressing or avoiding) their perceived negative emotions by writing down their deepest feelings and thoughts and gets the meaning or the wisdom of the grief they experienced, as well as being able to use others' perspective of their perceived grief, the perceived prolonged grief would be reduced (Pennebaker, 2011). The main hypothesis of the present study is that there are differences in the effect of expressive writing on the levels of grieving between the experimental group (expressive writing) and the control group. An additional hypothesis is that there is a significant reduction in the participants' levels of grieving in the experimental group after expressive writing. Both hypotheses would be tested using the experimental method. The second sequel was to determine the dynamics of emotions and thoughts of grief during writing three days in a row by means of a qualitative content analysis. Additionally, it is also thought that there are various psychological dynamics with regard to emotional disclosure (both positive and negative), the ability to see their grief from others' perspective, as well as the meaning making or wisdom of the grief events. In order to describe these, a content analysis was carried out on the basis of the ability to follow the writing instructions and the themes appearing in the texts.

\section{Reducing grief by means of expressive writing}

The study by (Leblanc et al., 2019) showed that grieving is the psychobiological response to the death of loved ones as indicated by sadness, longing, floating emotions, and loss of appetite and sleep. This causes problems for some people (especially in the early adulthood). They will be overwhelmed with the feeling of loss itself since they will tend to bury it and inhibit the expressions by reason of controlling their emotions. According to (Stroebe,M., Schut., 2005), controlling emotions seems good, but expressing it is also necessary. Narrative writing (Bahiyah \& Savitri, 2018; Savitri, Takwin, \& Ariyanto, 2019) can be a means for an individual to express feelings since he or she actively manage emotions arising due to recalling the events of grief directly. Dealing with emotions arising due to recalling negative events an individual can actively be helped reduce the impact of inhibition of emotions and facilitate the regulation of emotions(Watson \& Pennebaker, 1989)

The mechanism underlying the adaptive process of expressive writing is to express emotions that will encourasge individuals to deal with their emotions, instead of keeping, suppressing or avoiding them. Expressing emotions in written form will help individuals obtain psychological benefits of (1) coping with emotions actively. According to (Huffine, Folkman, \& Lazarus, 1989), an individual will feel better when they face directly the sources that make them feel depressed; thus, the painful responses arising when recalling the events of loss become reduced since the role of cognition is more dominant when writing it. Cognition used when doing the writing serves as a kind of acceptance or confession of the events of loss.

On the other hand, writing can generate the benefit of self-perception of an active agent. Through writing, an individual can see themselves as problem-solving agents, who have control over themselves to solve problems; 2) Reconstructing negative experiences into narration. (Lazlo.J, 2008) stated that, by engaging in narrative thinking, people would translate their lives into easy-to-understand stories. Writing down their life could help them organize events into a text, which contains goals and social 
relationships, helping the individual rearrange their experiences. There is also the potential to improve the way of thinking that will appear in terms of clarity and storyline, thus encouraging them to better understand the events they experienced and how to deal with them; 3) Assimilating trauma with other memories. The writing process gives individuals the opportunity to recall traumatic episodic memories (what happened) with abstract semantic memories (meaning); thus, when the individual allows himself to recall the negative events and write it down, the events will be arranged into a more structured way, integrating episodic and semantic memories containing narration of past events into interpretation, leading to reduced or less intense negative emotions. This is supported by the findings (Anderson \& Levy, 2009) study that repression of unwanted memory often has a little to do with other memories, leading memories to become less comprehensive and the focus of attention being only on the repressed memories, making them naturally traumatized.

\section{Method}

\section{Samples and Procedures}

The present study used the sequential explanatory design (Creswell, 2013) to test the hypothesis. The first stage was performed by the method of experimental pre-post test independent matching group design. The second stage was to describe the mechanism underlying the effects of expressive writing on the dependent variable, the level of grieving, by using the content (qualitative) analysis on the basis of the themes emerging from expressive writing instructions for 3 consecutive days.

The first stage of the experiment was performed to test whether the manipulation of independent variable, i.e., writing techniques (expressive vs. control), would cause differences in the levels of grieving between the experimental group (expressive writing) and the control group (non-expressive writing or topics of daily activities), and whether there is a decrease in the levels of grieving in the experimental group as indicated by the pre-test and post-test.

In doing so, a total of 30 participants ( 7 men, 23 women, Mage $=21.2, \mathrm{SD}=1.2$ ) was recruited, who were selected through a public announcement. The participants' levels of grieving were subsequently measured using the instrument Inventory of Complicated Grief (ICG) (Prigerson et al., 2005). As baseline participants, only those with a total ICG score of greater than or equal to 25 were selected as samples. The participants' demographic data are shown in Table 1.1. below.

Table 1. Participants' demographic description

\begin{tabular}{ccccc}
\hline Name & Gender & Age & $\begin{array}{c}\text { Age of the Event of } \\
\text { Loss }\end{array}$ & Deceased Parent \\
\hline AP & F & $26 \mathrm{yr}$ & 11 years & Mother \\
NF & $\mathrm{F}$ & $29 \mathrm{yr}$ & 1 years & Father \\
NT & $\mathrm{F}$ & $22 \mathrm{yr}$ & 2 years & Mother \\
MG & $\mathrm{F}$ & $24 \mathrm{yr}$ & 7 months & Father \\
RM & $\mathrm{M}$ & $26 \mathrm{yr}$ & 10 months & Mother \\
KA & $\mathrm{M}$ & $31 \mathrm{yr}$ & 3 years & Mother \\
AF & $\mathrm{F}$ & $26 \mathrm{yr}$ & 15 years & Father \\
RK & $\mathrm{F}$ & $22 \mathrm{yr}$ & 4 years & Father \\
EL & $\mathrm{F}$ & $21 \mathrm{yr}$ & 4 years & Mother \\
MA & $\mathrm{F}$ & $24 \mathrm{yr}$ & 6 years & Mother \\
NR & $\mathrm{F}$ & $26 \mathrm{yr}$ & 5 years & Mother \\
SU & $\mathrm{F}$ & $28 \mathrm{yr}$ & 6 years & Mother \\
FY & $\mathrm{F}$ & $31 \mathrm{yr}$ & 3 years & Mother \\
MR & $\mathrm{F}$ & $29 \mathrm{yr}$ & 8 years & Father \\
AN & $\mathrm{F}$ & $28 \mathrm{yr}$ & 2 years & Father \\
MD & $\mathrm{F}$ & $21 \mathrm{yr}$ & 2 years & Father \\
CH & $\mathrm{F}$ & $23 \mathrm{yr}$ & 1 years & Mother \\
\hline
\end{tabular}




\begin{tabular}{ccccc} 
RC & F & $28 \mathrm{yr}$ & 5 years & Mother \\
AW & F & $26 \mathrm{yr}$ & 4 years & Father \\
PL & $\mathrm{F}$ & $24 \mathrm{yr}$ & 14 years & Mother \\
IM & M & $23 \mathrm{yr}$ & 1 years & Father \\
MU & $\mathrm{F}$ & $23 \mathrm{yr}$ & 3 years & Mother and Father \\
BS & $\mathrm{M}$ & $26 \mathrm{yr}$ & 1 years & Father \\
TS & $\mathrm{M}$ & $24 \mathrm{yr}$ & 7 months & Father \\
AU & $\mathrm{F}$ & $24 \mathrm{yr}$ & 4 years & Father \\
DC & $\mathrm{F}$ & $19 \mathrm{yr}$ & 1 years & Father \\
AM & $\mathrm{F}$ & $24 \mathrm{yr}$ & 7 years & Father \\
AF & $\mathrm{M}$ & $29 \mathrm{yr}$ & 8 years & Father \\
BK & $\mathrm{M}$ & $27 \mathrm{yr}$ & 1 years & Father \\
JB & $\mathrm{F}$ & $25 \mathrm{yr}$ & 6 years & Father \\
\hline
\end{tabular}

The pre-test produced baseline Inventory of Complicated Grief (Prigerson et al., 1995) scores, which were matched (Cash, Stankovi, \& Štorga, 2016) to serve as a basis for dividing the experimental and control groups with the following steps: Ranking participants' CGI scores for pairing.

Table 2. Pre-test subjects' scores

\begin{tabular}{ccc|ccc}
\hline No. & Initial & Score & No. & Initial & Score \\
\hline 1 & AP & 54 & 16 & FY & 31 \\
2 & IM & 57 & 17 & CH & 36 \\
3 & MD & 53 & 18 & NF & 38 \\
4 & AF & 53 & 19 & DC & 32 \\
5 & SU & 51 & 20 & RC & 30 \\
6 & AM & 51 & 21 & KA & 30 \\
7 & MU & 48 & 22 & NR & 29 \\
8 & NT & 46 & 23 & PL & 29 \\
9 & RK & 43 & 24 & EL & 28 \\
10 & BS & 42 & 25 & TS & 28 \\
11 & AW & 39 & 26 & BK & 28 \\
12 & MG & 35 & 27 & MR & 27 \\
13 & AG & 38 & 28 & RM & 26 \\
14 & AN & 35 & 29 & MN & 26 \\
15 & JB & 38 & 30 & AU & 25 \\
\hline
\end{tabular}

1) Pairing subjects on the basis of the rankings; the first pair consisted of subject 1 and subject 2; the second pair consisted of subject 3 and subject 4, and so on; 2) Selecting randomly from each pair subjects to be distributed to the Experiment Group (EG) and Control Group (CG) using the matching technique. The EG and CG are shown in Table 2. 
Table 3. Group distribution by means of the matching method

\begin{tabular}{ccc}
\hline & EG & \\
\hline No. & Initial & Score \\
\hline 1 & AP & 54 \\
4 & AF & 53 \\
5 & SU & 51 \\
8 & NT & 46 \\
9 & RK & 42 \\
12 & NF & 36 \\
13 & MG & 35 \\
16 & AN & 35 \\
17 & FY & 31 \\
20 & KA & 30 \\
21 & EL & 28 \\
24 & NR & 29 \\
25 & MR & 27 \\
28 & RM & 26 \\
29 & MN & 26 \\
\hline
\end{tabular}

\begin{tabular}{ccc}
\hline & CG & \\
\hline No. & Initial & Score \\
\hline 2 & IM & 57 \\
3 & MD & 53 \\
6 & AM & 51 \\
7 & MU & 48 \\
10 & BS & 43 \\
11 & AW & 39 \\
14 & AG & 38 \\
15 & JB & 38 \\
18 & CH & 36 \\
19 & DC & 32 \\
22 & RC & 30 \\
23 & PL & 29 \\
26 & BK & 28 \\
27 & TS & 28 \\
30 & AU & 25 \\
\hline
\end{tabular}

After the matching procedure, manipulation was performed by instructing the participants to write for 3 consecutive days with duration of 15 minutes per day. The Experiment Group (EG) participants were asked to write expressively their feelings about the loss of their parents, while the Control Group (CG) participants were only asked to write their daily activities and were not allowed to write about their feelings or opinions.

The writing instructions used for the manipulation of independent variable are as follows: Instructions for the experiment group

\section{Day 1 (emotional disclosure)}

Not everyone experiences a loss as you feel; please write about your deepest thoughts and feelings about the loss of your father/mother. At the time of writing, release your emotions and explore the event and how it affected you. You can write down how it happened, how you felt when it happened and how do you feel now. (Example: I had an accident 4 years ago. I had to stay in the hospital for months, I felt very bad because I was worried about losing my future, etc.)

Day 2 (see from others' perspectives)

On this second day, try to think of associating the event of a loss you experienced with other things outside of yourself, with matters relating to your relationship with your family, or your closest friends, how others think (family, friends and close friends) of you, how the event affected your activities, as well as your work.

Day 3 (making meaning or wisdom)

On this third day, you stay focused on your emotional state and thoughts about the event, but try to use different perspectives and points of view from those you think about, try to think and look for wisdom that might be hidden from the event, and how it influences and shapes you to be what you are today. If possible, end your writing today by writing a letter to your father/mother, whatever you want to convey to them. 


\section{Instructions for the control group (non-expressive writing)}

For the next three days, write down your daily activities, from getting out of bed until the evening (both planned and done). Do not write about your feelings about your event of a loss, and do not write about your opinion of the event. Write down WHAT happens every day, write in the form of activities. Example: I wake up at 7; I used to pray and then tidy up the bedroom and have breakfast. Later in the afternoon I will meet my friend and then in the evening I will watch a movie, etc.)

The measure used was the Inventory of Complicated Grief (Prigerson et al., 1995) with 19 items using a Likert scale with 5 alternative answers, starting from 0 for Never experienced, 1 Rarely experienced, 2 Sometimes experienced, 3 Often experienced, 4 Very often experienced. The measure was adapted by translating it into Indonesian, and then translating it back to English. It was then validated by using three experts, consisting of 1 clinical psychologist, 1 social psychologist and 1 head of the funeral home.

The reliability test showed an alpha Cronbach of 0.9 , meaning that the measure was reliable. Then, since independent T-tests and paired T-tests for pre-post tests were used, requiring normal and homogeneous data distribution, data normality and homogeneity were tested. Results of the KolmogorovSmirnov test of the normal data distribution showed a p-value of $0.1(p>0.05)$, while results of the Lavene test of data homogeneity showed a $\mathrm{p}$-value $=0.834(\mathrm{p}>0.05)$, meaning that data were homogeneously distributed.

The whole manipulation (intervention) procedure in this experiment was as follows; 1 ) in the prestudy, participants were asked to download the DU recorder application, which is a screen recorder application that will record participants' face and writing via Google Play Store; 2) the secondary variables (extraneous variable) were determined, which are expected to have an effect on the manipulation of independent variables (expressive writing): a) the age of the event, controlled for by selecting participants who experienced grief for more than 6 months(Prigerson et al., 1995) b) the age of the participant, controlled for only for those of early adulthood; c) the baseline level of grief, only those with a baseline score of 25 and above being selected, which could be categorized as experiencing prolonged grief; 3) randomization using the matching technique to ensure internal validity, in which the participants with equal baseline ICG scores in the experimental group and control group were paired (see Table 3.1); 4) a readability test on 10 people outside the participants was performed to maximize variation in order to ensure that instructions for the experimental and control groups were completely different; 4) After randomization using the matching technique, the participants were given written and audio writing instructions (by means of recorded instructions), which would be followed for 3 consecutive days of writing for 15 minutes/day; 5) participants wrote using the DU recorder at the place determined by the participants for privacy and calm; 6) After writing for 3 days in a row, 15 minutes/day, participants sent their writing results to the specified email address; 7) participants fill in the post-test, Inventory of Complicated Grief.

In the second stage, the content (qualitative) analysis was carried out on the narrative of the experimental group participants based on the expressive writing instructions and coding would be carried out as follows: 1) Determine the characteristics of complicated grief based on factors in the Complicated Inventory Grief (CIG), consisting of: (Being overwhelmed with thoughts of the deceased, Always looking for and feeling missing the deceased, Not believing that the deceased is dead, Crying constantly, Remaining gaping or stunned by the death of the deceased, Not accepting the death of the deceased); 2) Conduct content analysis: whether the 6 characteristics of the complicated grief were present in the participants' writing contents; 3 ) Conduct content analysis: whether participants could comply with the expressive writing instructions that led participants to: (Day 1: be able to express the deepest thoughts and feelings on the first day and identify their thoughts and feelings when the events occur to activate the functions of self-disclosure., Day 2: be able to encourage participants to see the impact of the events of a loss and to think about how the participant's relationship with other people related to the event, to activate others' perspectives, Day 3: be able to encourage participants to find meaning in the event of a loss or to take lessons from the event, Find themes written by the participants during 3 days in a row of writing, Conduct a comparative analysis among participants of the contents written for 3 consecutive days to determine the psychological dynamics among the participants). 
Table 3. Content analysis Form

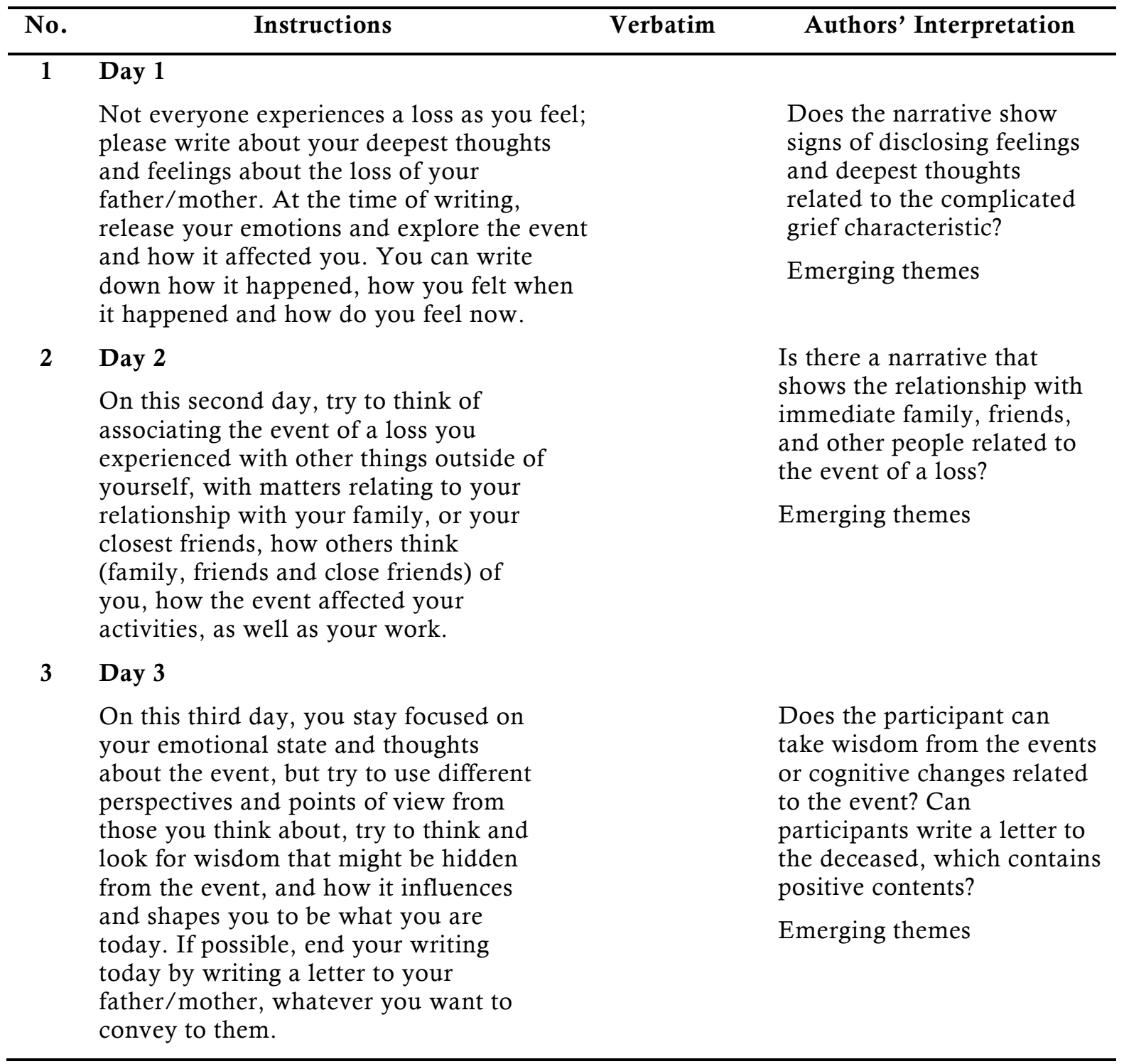

\section{Results and Discussion}

The hypotheses to be tested in the present study were whether there are differences in the levels of grieving between the experimental group performing expressive writing and the control group performing non-expressive writing (neutral) and whether there is a decrease in the levels of grieving (CGI score) of participants in the experimental group before and after expressive writing. Results showed that the pre- and post-writing results for the experimental group differed significantly, whereas for the control group it did not differ significantly, as shown in the following table: 
Table 4. Results of paired T-test of pre- and post-expressive writing

\begin{tabular}{ccccccc}
\hline & \multicolumn{2}{c}{ Experiment } & \multicolumn{2}{c}{ Control } & Sig(2-tailed) & T-value \\
\hline & Pre & Post & Pre & Post & $0.000^{*}$ & 7.08 \\
\hline \multirow{2}{*}{ Mean } & 36.73 & 25.73 & 38.33 & 36.80 & 0.133 & 1.59 \\
\hline
\end{tabular}

*Significant at $p<0.05$.

These results indicate that expressive writing for three consecutive days with duration of 15 minutes managed to reduce the levels of grieving in the experimental group, but not in the control group. Thus, the first hypothesis is supported.

The second hypothesis that there are differences in the levels of grieving between the experimental and control groups was tested by performing an independent T-test of the post-writing grieving scores of the control and the experimental groups. The results are shown in the following table.

Table 5. Results of independent t-test of samples

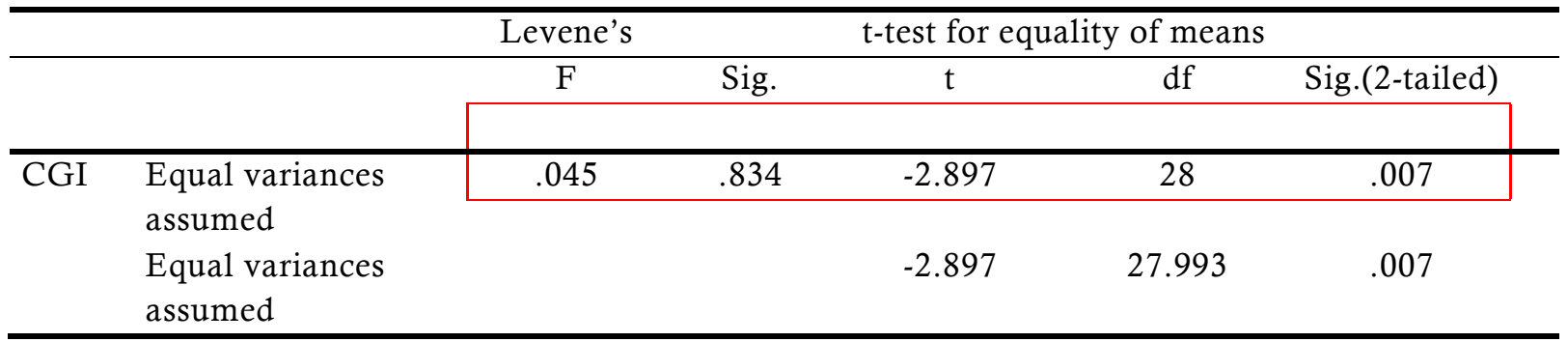

The independent T-test showed that was a significant difference in the levels of grieving $(\mathrm{p} \leq 0.05)$ between the experimental (expressive writing) $(\mathrm{M}=25.73$; $\mathrm{SD}=10.54)$ and control groups (nonexpressive writing) $(\mathrm{M}=36.80, \mathrm{SD}=10.38)$, with a $\mathrm{t}$-value of -2.89 . Thus, the second hypothesis is supported.

\section{Content Analysis}

To describe the psychological dynamics of grief by means of the participants' expressive writing, a content analysis (Krippendorff, 2004; Mayring, 2014) was performed. The purpose of content analysis is to determine whether participants can properly follow the expressive writing instructions. The analysis was carried out by two independent raters. Subsequently, content analysis was performed to find the themes emerging from the participants' writings that matched or did not matched the instructions in order to describe the patterns of the participants' narratives.

Results of the analysis of participants' ability to follow the instructions are shown in Table 5. The themes emerging from the participants' narratives are shown in Table 5. as follows. 
Table. 5. Raters' interpretation of the success of following instructions for the experimental group

\begin{tabular}{|c|c|c|c|c|c|c|c|c|c|c|c|c|c|c|c|c|c|c|c|c|c|c|c|c|}
\hline \multirow{2}{*}{ 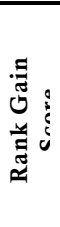 } & \multirow{2}{*}{ 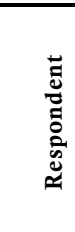 } & \multirow{2}{*}{ 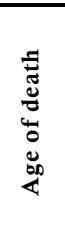 } & \multirow{2}{*}{ 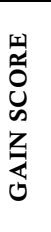 } & \multirow{2}{*}{ 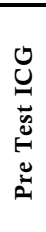 } & \multicolumn{6}{|c|}{$\begin{array}{c}\text { Day 1 } \\
\text { (Success of writing down the } \\
\text { deepest feelings and thoughts } \\
\text { openly) }\end{array}$} & \multicolumn{7}{|c|}{$\begin{array}{c}\text { Day } 2 \\
\text { (Success of writing down others' } \\
\text { perspectives on self and grief } \\
\text { events) }\end{array}$} & \multicolumn{6}{|c|}{$\begin{array}{c}\text { Day } 3 \\
\text { (Success of writing down } \\
\text { wisdom or meaning of the } \\
\text { grief event) }\end{array}$} & \multirow{2}{*}{$\begin{array}{c}\text { Pos } \\
\mathbf{t} \\
\text { Tes } \\
\mathbf{t} \\
\text { IC } \\
\text { G } \\
\end{array}$} \\
\hline & & & & & $\begin{array}{c}\text { Par } \\
.1\end{array}$ & $\begin{array}{c}\text { Par. } \\
2\end{array}$ & $\begin{array}{c}\text { Par } \\
.3\end{array}$ & $\begin{array}{c}\text { Par } \\
.4\end{array}$ & $\begin{array}{c}\text { Par. } \\
5\end{array}$ & $\begin{array}{c}\text { Par } \\
.6\end{array}$ & $\begin{array}{c}\text { Par } \\
.1\end{array}$ & $\begin{array}{c}\text { Par } \\
.2\end{array}$ & $\begin{array}{c}\text { Par } \\
.3\end{array}$ & $\begin{array}{c}\text { Par } \\
4\end{array}$ & $\begin{array}{c}\text { Par } \\
.5\end{array}$ & $\begin{array}{c}\text { Par } \\
.6\end{array}$ & $\begin{array}{c}\text { Par } \\
.7\end{array}$ & $\begin{array}{c}\text { Par } \\
.1\end{array}$ & $\begin{array}{c}\text { Par } \\
.2\end{array}$ & $\begin{array}{c}\text { Par } \\
.3\end{array}$ & $\begin{array}{c}\text { Par } \\
4\end{array}$ & $\begin{array}{c}\text { Par } \\
.5\end{array}$ & $\begin{array}{c}\text { Par. } \\
6\end{array}$ & \\
\hline 1 & NF & $1 \mathrm{yr}$ & 19 & 36 & $X$ & $\sqrt{ }$ & $X$ & $\sqrt{ }$ & $X$ & $\sqrt{ }$ & $\mathrm{x}$ & $\mathrm{x}$ & $\sqrt{ }$ & $\mathrm{x}$ & $\sqrt{ }$ & - & - & $\sqrt{ }$ & $\sqrt{ }$ & $\sqrt{ }$ & $\sqrt{ }$ & $\sqrt{ }$ & $\sqrt{ }$ & 17 \\
\hline 2 & SU & $6 \mathrm{yr}$ & 17 & 53 & $X$ & $\sqrt{ }$ & $\sqrt{ }$ & - & - & - & $\sqrt{ }$ & $\sqrt{ }$ & $\sqrt{ }$ & - & - & - & - & $\sqrt{ }$ & $\sqrt{ }$ & $\sqrt{ }$ & $\sqrt{ }$ & - & - & 36 \\
\hline 3 & MR & $8 \mathrm{yr}$ & 16 & 27 & $X$ & $\sqrt{ }$ & $\sqrt{ }$ & $\sqrt{ }$ & $\sqrt{ }$ & - & $\sqrt{ }$ & $\mathrm{x}$ & $\sqrt{ }$ & $\mathrm{x}$ & - & - & - & $\sqrt{ }$ & $\sqrt{ }$ & $\sqrt{ }$ & - & - & - & 11 \\
\hline 4 & $\mathrm{AF}$ & 15 & 15 & 53 & $\sqrt{ }$ & $\sqrt{ }$ & $\sqrt{ }$ & - & - & - & $\mathrm{x}$ & $\sqrt{ }$ & $x$ & $\sqrt{ }$ & - & - & - & $\sqrt{ }$ & $\sqrt{ }$ & $\sqrt{ }$ & - & - & - & 38 \\
\hline 5 & NT & $\begin{array}{c}\mathrm{yr} \\
2 \mathrm{yr}\end{array}$ & 14 & 46 & $\sqrt{ }$ & $\sqrt{ }$ & $\sqrt{ }$ & $\sqrt{ }$ & $\sqrt{ }$ & $\sqrt{ }$ & $\sqrt{ }$ & $\sqrt{ }$ & $x$ & $\sqrt{ }$ & $\sqrt{ }$ & $\mathrm{x}$ & $\sqrt{ }$ & $\sqrt{ }$ & $\sqrt{ }$ & $\sqrt{ }$ & - & - & $\sqrt{ }$ & 32 \\
\hline 6 & $\mathrm{RM}$ & $\begin{array}{l}10 \\
\mathrm{mt}\end{array}$ & 12 & 26 & $\sqrt{ }$ & $\sqrt{ }$ & $\sqrt{ }$ & $\sqrt{ }$ & $\sqrt{ }$ & - & $\mathrm{x}$ & $\sqrt{ }$ & $\mathrm{x}$ & $\sqrt{ }$ & - & - & - & $\sqrt{ }$ & $\sqrt{ }$ & - & - & - & - & 14 \\
\hline 7 & KA & $3 \mathrm{yr}$ & 12 & 30 & $X$ & $\sqrt{ }$ & $\sqrt{ }$ & $\sqrt{ }$ & $\sqrt{ }$ & - & $\sqrt{ }$ & $\sqrt{ }$ & $\sqrt{ }$ & - & - & - & - & $\sqrt{ }$ & $\sqrt{ }$ & - & - & - & - & 18 \\
\hline 8 & EL & $4 \mathrm{yr}$ & 12 & 28 & $\sqrt{ }$ & $\sqrt{ }$ & $\sqrt{ }$ & $\sqrt{ }$ & $\sqrt{ }$ & - & $\sqrt{ }$ & $\sqrt{ }$ & - & - & - & - & - & $\sqrt{ }$ & $\sqrt{ }$ & - & - & - & - & 16 \\
\hline 9 & $\mathrm{AN}$ & $2 \mathrm{yr}$ & 12 & 35 & $\sqrt{ }$ & $\sqrt{ }$ & - & - & - & - & $\mathrm{x}$ & $\sqrt{ }$ & $\sqrt{ }$ & $\sqrt{ }$ & $\sqrt{ }$ & $\sqrt{ }$ & $\sqrt{ }$ & $\sqrt{ }$ & $\sqrt{ }$ & $\sqrt{ }$ & - & - & - & 23 \\
\hline 10 & FY & $3 \mathrm{yr}$ & 11 & 31 & $X$ & $\sqrt{ }$ & - & - & - & - & $\mathrm{x}$ & $\sqrt{ }$ & $\sqrt{ }$ & $\sqrt{ }$ & $x$ & - & - & $\sqrt{ }$ & $x$ & $\sqrt{ }$ & - & - & - & 20 \\
\hline 11 & $\mathrm{AP}$ & $\begin{array}{l}11 \\
\text { yr }\end{array}$ & 10 & 54 & $\sqrt{ }$ & $\sqrt{ }$ & $\sqrt{ }$ & $\sqrt{ }$ & - & - & $\sqrt{ }$ & $\sqrt{ }$ & $\sqrt{ }$ & $\sqrt{ }$ & - & - & - & $\sqrt{ }$ & $\sqrt{ }$ & - & - & - & - & 44 \\
\hline 12 & $\mathrm{RK}$ & $4 \mathrm{yr}$ & 10 & 42 & $\sqrt{ }$ & $\sqrt{ }$ & $\sqrt{ }$ & $\sqrt{ }$ & $\sqrt{ }$ & - & $\mathrm{X}$ & $\sqrt{ }$ & X & $\sqrt{ }$ & - & - & - & $\sqrt{ }$ & $\sqrt{ }$ & - & - & - & - & 32 \\
\hline 13 & NR & $5 \mathrm{yr}$ & 6 & 29 & $\sqrt{ }$ & $\sqrt{ }$ & - & - & - & - & $X$ & $\sqrt{ }$ & - & - & - & - & - & $\sqrt{ }$ & $\sqrt{ }$ & - & - & - & - & 23 \\
\hline 14 & MG & $\begin{array}{c}7 \\
\text { mo }\end{array}$ & 6 & 41 & $\sqrt{ }$ & $\sqrt{ }$ & $\sqrt{ }$ & $\sqrt{ }$ & $\sqrt{ }$ & $\sqrt{ }$ & $X$ & $\mathrm{X}$ & $\sqrt{ }$ & $X$ & $\sqrt{ }$ & - & - & $\sqrt{ }$ & $\sqrt{ }$ & - & - & - & - & 35 \\
\hline 15 & $\mathrm{MN}$ & $6 \mathrm{yr}$ & 5 & 26 & $\sqrt{ }$ & $\sqrt{ }$ & $\sqrt{ }$ & - & - & - & $\mathrm{X}$ & $\mathrm{X}$ & $\sqrt{ }$ & - & - & - & - & $X$ & $\sqrt{ }$ & - & - & - & - & 21 \\
\hline${ }_{\mathrm{p}}^{(\mathrm{Suc}}$ & $\begin{array}{l}\text { uccess } \\
\text { instru } \\
\text { cessful } \\
\text { aragra }\end{array}$ & $\begin{array}{l}\text { of foll } \\
\text { ctions } \\
\text { parag } \\
\text { phs) } x\end{array}$ & $\begin{array}{l}\text { owin } \\
\text { (\%) } \\
\text { raphs } \\
100 \%\end{array}$ & & $\begin{array}{l}66 \\
\%\end{array}$ & $\begin{array}{c}100 \\
\%\end{array}$ & $\begin{array}{l}73 \\
\%\end{array}$ & $\begin{array}{l}60 \\
\%\end{array}$ & $46 \%$ & $\begin{array}{l}20 \\
\%\end{array}$ & $\begin{array}{l}40 \\
\%\end{array}$ & $\begin{array}{l}74 \\
\%\end{array}$ & $\begin{array}{l}53 \\
\%\end{array}$ & $\begin{array}{l}46 \\
\%\end{array}$ & $\begin{array}{l}26 \\
\%\end{array}$ & $6 \%$ & $\begin{array}{l}30 \\
\%\end{array}$ & $\begin{array}{l}93 \\
\%\end{array}$ & $\begin{array}{l}93 \\
\%\end{array}$ & $\begin{array}{l}46 \\
\%\end{array}$ & $\begin{array}{l}13 \\
\%\end{array}$ & $6 \%$ & $13 \%$ & \\
\hline (f & $\begin{array}{l}\text { Failur } \\
\text { instru } \\
\text { ailed } p \\
\text { aragra }\end{array}$ & $\begin{array}{l}\text { to fol } \\
\text { ctions } \\
\text { aragra } \\
\text { hs) } x\end{array}$ & (\%) & & $\begin{array}{l}33 \\
\%\end{array}$ & $0 \%$ & $7, \%$ & $0 \%$ & $\begin{array}{c}6.6 \\
\%\end{array}$ & $0 \%$ & $\begin{array}{l}60 \\
\%\end{array}$ & $\begin{array}{l}26 \\
\%\end{array}$ & $\begin{array}{l}20 \\
\%\end{array}$ & $\begin{array}{l}20 \\
\%\end{array}$ & $6 \%$ & $6 \%$ & $0 \%$ & $7 \%$ & $7 \%$ & $0 \%$ & $0 \%$ & $0 \%$ & 0 & \\
\hline Not & writin & g (par & agrap & & $0 \%$ & $0 \%$ & $\begin{array}{l}20 \\
\%\end{array}$ & $\begin{array}{l}40 \\
\%\end{array}$ & $\begin{array}{c}46 . \\
\%\end{array}$ & $\begin{array}{l}80 \\
\%\end{array}$ & $0 \%$ & $0 \%$ & $\begin{array}{l}13 \\
\%\end{array}$ & $\begin{array}{l}34 \\
\%\end{array}$ & $68^{*}$ & $\begin{array}{l}88 \\
\%\end{array}$ & $0 \%$ & $0 \%$ & $7 \%$ & $\begin{array}{l}53 \\
\%\end{array}$ & $\begin{array}{l}87 \\
\%\end{array}$ & $\begin{array}{l}94 \\
\%\end{array}$ & $\begin{array}{c}87 \% \\
\mathrm{~S}\end{array}$ & \\
\hline
\end{tabular}

Unit of analysis = paragraphs; $\mathrm{X}=$ participant not following instructions; $\mathrm{V}=$ participants

following instructions; -: blank paragraphs.

As shown in Table 5. based on the rank gain score (score [post test CGI - CGI Pre-test score), the participants' grieving after writing shows the following patterns:

The most obvious pattern was shown by the participants' success of following the first day's instructions of writing down their deepest feelings and thoughts related to the grief events. All participants could follow $66 \%$ of instructions in the first paragraph and then increased to $100 \%$ in the second paragraph and gradually decreased in the subsequent paragraphs. The similar pattern was seen in the third day's instructions of finding wisdom and sending letters to the deceased. All of the participants succeeded in following the instructions (93\%), except for $\mathrm{MN}$ that failed to write meaning in the first paragraph, he/she also had the lowest gain score. In the second paragraph all of the participants could find meaning and write a letter to the deceased (93\%), except for FY, which then decreased in the following paragraphs. However, there were inconsistent patterns in responding to the second instruction of writing down other things outside of themselves and the perceived of grief. There were participants who succeed $(\sqrt{ })$ and some who failed (X). The content analysis showed that expressive writing with a pattern of emotional disclosure is effective in relieving grief (Sloan, Marx, \& Epstein, 2005). It naturally helped participants disclose their suppressed emotions and the disturbing ruminative patterns of thought (Baikie, 2008)

Basically, the instructions used were based on the expressive writing instructions of James W. Pannebaker (2004, p.12) which seek to recognize both positive and negative emotions associated with negative experiences (eg. grief, in the present study). In the present study, it was represented by the firstday instructions. The broadening of the perspective to prevent from being overwhelmed with emotions emanating from the grief events is represented by the second-day instructions. The re-interpretation as referred to in the theory of self-distancing, a condition of switching perspectives of negative experiences into new meanings (Park, Ayduk, \& Kross, 2016) is represented in the third-day instructions. 
In detail, based on the objectives of the first- and third-day writing instructions, the results of content analysis of exploring emotions are relatively successful. On the first day, all participants were able to follow the writing instructions to explore their emotions and recognize their emotions well (sample sentences: and no matter how strong I cried, my soul couldn't open her eyes (AF.1.1). That day, I lost a big part of my life. The house felt quiet without mama (NT.1.2))

With regard to the second-day instructions, there were irregular and inconsistent patterns. The instructions aimed at obtaining different perspectives from the participants' subjective perspectives on being likely to be overwhelmed with the grief event, did not successfully reveal it (sample sentences: I also do not know others' views of me, maybe I just live my life only because I have a breath, I don't know the rest, RK.2.1). In this sentence, RK tends not to want to know others' views of her. She tends to be hopeless. There are some participants who were able to use others' perspectives on themselves in the face of grief events, but they were not consistent (Even when I asked my friends, they said that it's normal for me to behave this way - away from my friends because I am still grieving. I stay away from my friends. NT, 2.1.); another thing that has changed is the way I treat older people; in my opinion, I have become more respectful and more polite. Even I help the elderly or people of my mother's age without any consideration (MR, 2.1).

With regard to the third-day instructions of taking wisdom and sending a letter, consistency and patterns are clearly seen in paragraphs 1 and 2. Some sample sentences include those from NF, who have the highest gain score, "There are much wisdom from this event. Papa teaches me remain strong in any condition and should be patient and maintain health and lifestyle" (NF, 3.1); MN, who had the lowest gain score, despite the difficulty in taking wisdom, still could see that there was wisdom, "In my opinion, there is only one wisdom behind my mother's death, she did not need to suffer from illness for too long, because when she was in the ICU and helpless to do anything, my heart was sad and hurt seeing it" $(\mathrm{MN}, 3.1)$.

\section{Emerging themes}

With regard to the first-day instructions of writing down the deepest feelings and thoughts, the emerging themes among the participants showed similar themes of grief: shock, confusion, sadness, crying, anger, and questioning of why I had to experience it, and a desire to get a chance to be together again. These themes are similar to the patterns of grief studied by (Hamilton I.J, 2016) (2016). On the third day, instructions to find wisdom were successfully written down by the participants and produced themes of independence, apology to the deceased, commitment to be better, more responsible, and be able to build closeness with other members of the family besides the deceased. These are in line with Calhoun, et.all (2010) study, stating that the event of grief due to the loss of parents (either one or both) may be an experience of self-maturity.

\section{Conclusion}

There were significant differences in the levels of grief between the participants in the experimental group (expressive writing) and those of the participants in the control group (nonexpressive writing/daily activities). The levels of grief of the participants who performed expressive writing decreased significantly. The results of content analysis showed that the first-day instructions succeeded in helping participants disclose and recognize the emotions when experiencing grief. The third-day instructions were also able to encourage participants to think and reinterpret the wisdom behind the grief event. The success of the first- and third-day instructions was not the case with the second-day instructions which asked participants to broaden their perspectives. This is an interesting finding. Despite the participants' inability to use others' perspectives in viewing their grief, but the levels of grief could be decrease by the participants' ability to disclose themselves and their emotions and take wisdom from their grief events. 


\section{References}

Anderson, M. C. (2004). Neural Systems Underlying the Suppression of Unwanted Memories. Science, 303(5655), 232-235. doi:10.1126/science.1089504

Bahiyah, S. \& Savitri, S. I (2018). Validasi Struktur Internal Alat Ukur Refleksi Diri Adaptif melalui CFA. Jurnal Psikologi, Vol.45, 107-131.

Baikie (2008). Who does expressive writing work for? Examination of alexithymia, splitting, and repressive coping style as moderators of the expressive writing paradigm. The British Psychological Society.

Boals, A (2012). The Use of Meaning Making in Expressive Writing: When Meaning is beneficial. Journal of Social and Clinical Psychology, Vol. 31, No. 4, 2012, pp. 393-40939. Guilford Publications, Inc.

Bonanno, G. A., Wortman, C. B., Lehman, D. R., Tweed, R. G., Haring, M., Sonnega, J.,\& Nesse, R. M. (2002). Resilience to loss and chronic grief: a prospective study from preloss to 18-months postloss. Journal of personality and social psychology, 83(5), 1150.

Bonanno, G. A., Goorin, L., \& Coifman, K. G. (2008). Sadness and grief. Handbook of emotions, 3, 797 806.

Bowlby, E. J. M. (2008). Loss-Sadness and Depression: Attachment and Loss (Vol. 3). Random House.

Calhoun, L.G., Tedeschi, R.G., Cann, A. and Hanks, E.A., 2010. Positive Outcomes Following Bereavement: Paths to Posttraumatic Growth. Psychologica Belgica, 50(1-2), pp.125-143. DOI: http://doi.org/10.5334/pb-50-1-2-125

Cash, P., Stanković, T., \& Štorga, M. (2016). An Introduction to Experimental Design Research. Experimental Design Research, 3-12. doi:10.1007/978-3-319-33781-4_1

Cresswell, J.C., (2008) Research Design: Quantitatvie, Qualitative and Mixed Method Approach. Sage Publication

Fitria,I., Faradina, S., Rizqina,F., Jannah, T., Fajri, A., Hadi,F., Sari, R,M, Nurul A'la. Menulis Dkspresif untuk Anak Jalanan: Suatu Metode Terapi Menulis dalam Diary Melalui Modul Eksperimen. ISSN: 2503-3611. Jurnal Psikoislamedia.Volume 1, Nomor 1, April 2016

Hamilton, I. J. (2016). Understanding grief and bereavement. British Journal of General Practice, 66(651), 523-523. doi:10.3399/bjgp16x687325

Huffine, C. L., Folkman, S., \& Lazarus, R. S. (1989). Psychoactive Drugs, Alcohol, and Stress and Coping Processes in Older Adults. The American Journal of Drug and Alcohol Abuse, 15(1), 101-113. doi: $10.3109 / 00952998908993403$

Krippendorff.K (2004) Content Analysis and Its Methodology. Sage Publication

Kacewicz, E., Slatcher, R. B., \& Pennebaker, J. W. (2007). Expressive writing: An alternative to traditional methods. In Low-cost approaches to promote physical and mental health (pp. 271-284). Springer, New York, NY.

Lazlo, J. (2008) The science of Stories. Routledge. Published in the USA and Canada by Routledge 270 Madison Avenue, New York, NY 100

LeBlanc, N. J., Simon, N. M., Reynolds, C. F., Katherine Shear, M., Skritskaya, N., \& Zisook, S. (2019). Relationship Between Complicated Grief and Depression: Relevance, Etiological Mechanisms, and Implications. Neurobiology of Depression, 231-239. doi:10.1016/b978-0-12-813333-0.00020-2

Lu.Q., Gallagher, M.W., Loh., A., Young,L. (2018). Expressive Writing Intervention Improves Quality of Life Among Chinese-American Breast Cancer Survivors: A Randomized Controlled Trial. The Society of Behavioral Medicine.

Mayring, P.(2014) Qualitative Content Analysis. Theoretical Foundation, Basic Procedures and Software Solution Klagenfurt, Austria.

Park., J.Y., Ayduk, O., \& Kross.E., (2016) Emotion. American Psychological Association, Vol. 16, No. 3, 349-364

Pennebaker, J.W (2011) The Secret Life of Pronouns. Bloomberry Press.

Pennebaker, J. W., \& Chung, C. K. (2011). Expressive writing: Connections to physical and mental health. Oxford handbook of health psychology.

Prigerson, H. G., Maciejewski, P. K., Reynolds III, C. F., Bierhals, A. J., Newsom, J. T., Fasiczka, A., \& Miller, M. (1995). Inventory of Complicated Grief: a scale to measure maladaptive symptoms of loss. Psychiatry research, 59(1-2), 65-79. 
Prigerson, H. G., Frank, E., Kasl, S. V., Reynolds, C. F., Anderson, B., Zubenko, G. S., ... \& Kupfer, D. J. (1995). Complicated grief and bereavement-related depression as distinct disorders: preliminary empirical validation in elderly bereaved spouses. American journal of Psychiatry.

Rubin, M., Hawkins, B., Cobb, A., \& Telch, M. J. (2019). Emotional reactivity to grief-related expressive writing. Death Studies, 1-9. doi:10.1080/07481187.2019.1595219

N. Qonitatin, S. Widyawati, and G. Y. Asih, "Pengaruh Katarsis dalam Menulis Ekspresif sebagai Intervensi Depresi Ringan pada Mahasiswa," Jurnal Psikologi, vol. 9, no. 1, Mar. 2012.

Savitri, S.I., Takwin, B., Ariyanto, A.A., \& Noviyanti (2019) Refleksi Diri Melewati Peristiwa Retaknya Keluarga dalam Penulisan Naratif: Studi Analisis Isi. Jurnal Psikologi Sosial August 2019 DOI: $10.7454 /$ jps.2019.15

Stroebe, M. (2005). Complicated Grief : Conceptual Analysis of The Fielf. OMEGA, Vol. 52(1) 53-70, 2005-2006. Baywood Publishing

Stroebe, M (2010) The Dual Process Model of Coping with Bereavement: a Decade on* Omega, Vol. 61(4) 273-289, 2010. Baywood Publishing

Watson, D., \& Pennebaker, J. W. (1989). Health complaints, stress, and distress: Exploring the central role of negative affectivity. Psychological Review, 96(2), 234-254. doi:10.1037/0033-295x.96.2.234 